\title{
Planned Clinical Study Activity
}

National Cancer Institute

\section{Source}

National Cancer Institute. Planned Clinical Study Activity. NCI Thesaurus. Code C70726.

Any activity specified in a clinical study protocol that is anticipated to be performed during the execution of the study. 